\title{
ẢNH HƯỞNG ÁNH SÁNG VÀ DINH DƯỠNG TRONG QUÁ TRÌNH NHÂN GIỐNG RONG MƠ - SARGASSUM POLYCYSTUM C. AGARDH TỪ HỢP TỦ
}

\author{
Lê Như Hậu*, Vũ Thị Mo, Võ Thành Trung, Trần Văn Huynh, Trần Nguyễn Hà Vy \\ Viện Nghiên cứu và Úng dụng Công nghệ Nha Trang \\ - Viện Hàn lâm Khoa học và Công nghệ Việt Nam \\ "Email: lenhuhau2003@yahoo.com
}

Ngày nhận bài: 10-8-2013

\begin{abstract}
TÓM TÄT: Sự gia tăng tốc độ phát triển của cây giống và giảm rong tạp là hai khó khăn chính trong quá trình sản xuất giống rong Mo trong phòng thí nghiệm. Kết quả cho thấy hàm luợng dinh duỡng $\mathrm{NaNO}_{3}: \mathrm{KH}_{2} \mathrm{PO}_{4}=4: 0,4 \mathrm{mg} / \mathrm{L}$ và mức ánh sáng $510 \mu \mathrm{mol}$ photon $/ \mathrm{m}^{2} / \mathrm{s}$ tốt cho sự phát triển của cây rong Mo con. Trong thí nghiệm, rong tạp cũng được hạn chế bằng cách giảm cuờng độ ánh sáng. Cây giống đạt chiều cao $0,2 \mathrm{~cm}$ sau 2 tháng nuôi cây con tù̀ hợp tử và cây giống đạt chiều cao $2 \mathrm{~cm}$ sau 4,5 tháng nuôi trong bể tù cây con có chiều cao $0,2 \mathrm{~cm}$. Kết quả cho thấy, sự phát triển của cây con trong giai đoạn uoom giống tù 0,2 đến $2 \mathrm{~cm}$ trong phòng thí nghiệm là rất thấp. Vì lẽ đó, để có giống đáp ứng được tiêu chuấn cây giống sau thời gian uoom cần thiết phải tiến hành ươm giống ngoài tụ nhiên.
\end{abstract}

Tù khóa: Nhiệt độ, sản xuất gống nhân tạo, Sargassum polycystum, sinh truởng và phát triển, ánh sáng và dinh duỡng.

\section{MỞ ĐẦU}

Nguồn lợi rong Mơ tự nhiên ở ven biển Việt Nam rất lớn, sản lượng hàng năm khoảng 20.000 tấn khô và đem lại thu nhập cho người dân ven biển khoảng 150 tỷ đồng [5].

Rong Mơ có vai trò quan trọng trong sự cân bằng các hệ sinh thái ven biển như hấp thụ các chất dinh dưỡng trong nước, giảm thiểu sự ô nhiễm dinh dưỡng trong môi trường nước ven bờ, làm nơi trú ngụ, bãi đẻ cho các loài hải sản có giá trị như: Tôm, cua, cá, mực, hải sâm, cầu gai [6], sử dụng trong y học [1].

Tuy nhiên, hiện nay người dân ven biển của địa phương đang tiến hành khai thác nguồn lợi này theo lợi nhuận trước mắt với giá $7.000-8.500$ đồng/kg khồ (như khai thác quá sớm so với mùa vụ chính, không chừa lại phần gốc ...). Nguồn lợi rong Mơ bị giảm đi đáng kể, nhiều nơi đã bị khai thác cạn kiệt thậm chí nhiều bãi rong Mơ trở nên hoang hóa, không có nguồn giống bố mẹ để phục hồi, mà chưa có một giải pháp nào để đảm bảo chất lượng và phát triển bền vững nguồn nguyên liệu dược liệu quý giá này.

Để phát triển nuôi trồng thành công, vấn đề quan trọng nhất là cung cấp đủ nguồn giống. Mặc dù có 3 cách để sản xuất giống cho nuồi trồng kinh tế: cây con tái phát triển từ gốc bám, thu cây con từ các bãi rong tự nhiên và cây con từ nuôi hợp tử. Hai cách đầu là khó đáp ứng nhu cầu phát triển nuôi trồng thương phẩm bền vững bởi vì nguồn giống rong tự nhiên sẽ bị xâm hại nghiêm trọng, cách sản xuất giống từ hợp tử mới có thể đáp ứng được khối lượng cây giông $[7,10]$.

Các nước như Nhật, Hàn Quốc, Trung Quốc nhân giống cây con rong Mơ đã có 
phương pháp sản xuất cây giống nhân tạo bằng hơp tử trong phòng thí nghiệm và sau đó đem ra trồng ngoài tự nhiên cho mục đích phục hồi và sản xuât nuôi trồng có kết quả tốt. Trong khi với các loài rong Câu, rong Sụn, rong Nho có thể sử dụng phương pháp nhân giông dinh dưỡng cho kêt quả nhanh hơn so với các phương pháp bằng bào tử.

Tuy nhiên, hiện nay nước ta chưa có cở sở nào nghiên cứu sản xuất giống rong Mơ để có nguồn giống phục vụ cho các giải pháp phục hồi cũng như nguồn giống để phục vụ nuôi trồng nhằm góp phần phát triển bền vững các bãi rong Mơ ở ven biển Việt Nam. Để hoàn thiện dần quy trình kỹ thuật nhân giống và nuôi trồng rong Mơ ở Việt Nam. Chúng tôi tiến hành "Nghiên cứu ảnh hưởng ánh sáng và dinh dưỡng lên sự phát triển của cây rong Mơ con trong giai đoạn từ hợp tử cho đến cây giống cao $0,5 \mathrm{~cm}$ ".

\section{PHƯONG PHÁP}

\section{Nguồn giống}

Rong Mơ (Sargassum polycystum) trưởng thành $(\Phi$ và $\delta$ ) có mang thỏi sinh sản được thu từ Sông Lô, Nha Trang $\left(12^{\circ} 9^{\prime} 27,11 " \mathrm{~N}\right.$, $\left.109^{\circ} 12^{\prime} 50,92^{\prime \prime E}\right)$ chuyển về phòng thí nghiệm Viện Nghiên cứu và Ứng dụng Công nghệ Nha Trang. Rửa rong bằng nước biển (đã lọc qua lưới lọc phytoplanton) để loại bỏ chất bẩn và phụ sinh. Nuôi chung rong cái và đực trong các bể kính chứa 80 lít nước biển và có sục khí.

Sau 2 ngày thuần dưỡng, cây rong được đưa ra khỏi bể, để kích thích khô trong điều kiện phòng $\left(28-30^{\circ} \mathrm{C}\right)$ từ 30 phút, sau đó cho rong vào bể thủy tinh $(60 \times 50 \times 40 \mathrm{~cm})$ dung tích 80 lít, độ mặn $30-32 \%$, nhiệt độ $28-30^{\circ} \mathrm{C}$ có sục khí. Sau 24 giờ, vớt rong ra khỏi bể. Sử dụng vợt để thu hợp tử và chổi lông mền để quét hợp tử lên bề mặt của các mảnh san hô (3 $\times 5 \mathrm{~cm})$ và dây thừng bằng nylon có đường kính 5 mm [7].

\section{Bố trí thí nghiệm}

Bốn bể thủy tinh với dung tích $100 \mathrm{~L}$, mỗi bể chứa $80 \mathrm{~L}$ nước biển và được bổ sung với một trong bốn nồng độ muối dinh dưỡng theo tỷ lệ $\mathrm{NaNO}_{3}: \mathrm{KH}_{2} \mathrm{PO}_{4}$ như sau: Nồng độ 1 là 4
: $0,4 \mathrm{mg} / \mathrm{L}$; nồng độ 2 là $8: 0,8 \mathrm{mg} / \mathrm{L}$; nồng độ 3 là $12: 1,2 \mathrm{mg} / \mathrm{L}$; nồng độ 4 là $16: 1,6 \mathrm{mg} / \mathrm{L}$ ).

Bốn lồng lưới hình trụ (đường kính $20 \mathrm{~cm}$ và cao $30 \mathrm{~cm}$ ) được bọc bằng lưới nylon để điều chỉnh ánh sáng theo 4 mức sau: mức 1.1: $165 \pm 22 \mu \mathrm{mol}$ photon $/ \mathrm{m}^{2} / \mathrm{s}$; mức 1.2: $310 \pm$ $25 \mu \mathrm{mol}$ photon $/ \mathrm{m}^{2} / \mathrm{s}$; mức $1.3: 510 \pm 50 \mu \mathrm{mol}$ photon $/ \mathrm{m}^{2} / \mathrm{s}$ và mức 1.4: $710 \pm 43 \mu \mathrm{mol}$ photon $/ \mathrm{m}^{2} / \mathrm{s}$, được sử dụng và đặt trên đáy mỗi bể theo chiều thẳng đứng.

15 mảnh san hô và 15 đoạn dây thừng dài $10 \mathrm{~cm}$ có hợp tử đã bám trên bề mặt, được sử dụng cho mỗi bể. Đặt 3 mảnh san hô và 3 đoạn dây thừng trong mỗi lồng lưới hình trụ.

Thí nghiệm được tiến hành trong 195 ngày. Nước trong các các lô thí nghiệm có cường độ ánh sáng và hàm lượng các chất dinh dưỡng khác nhau đều có trong cùng độ mặn, nhiệt độ, dòng chảy bằng máy bơm LIFETECH AP1200, $8,5 \mathrm{~W}$. Độ mặn được điều chỉnh 30-32\%o bằng cách thêm nước cất hoặc thêm muối ăn và đo bằng khúc xạ kế - Salinometer (Shibuya Japan). Nhiệt độ được duy trì $28-30^{\circ} \mathrm{C}$ bằng thiết bị ổn định nguồn nhiệt - Scientific Aquarium Reisea LX 502 CX - Japan. Nước được thay và bổ sung dinh dưỡng hàng tuần. Đo chiều dài, chiều rộng lá và số lượng lá của các cây con định kỳ 15 ngày/lần bằng kính hiển vi hoặc kính lúp.

\section{KẾT QUẢ NGHIÊN CÚU}

\section{Ảnh hưởng dinh dưỡng đến phát triển của cây giống rong Mo}

Ảnh hưởng của các nồng độ dinh dưỡng trên sự phát triển của cây con rong Mơ theo thời gian từ khi bắt đầu từ hợp tử đển 60 ngày, cho thấy cây giống phát triển ở hai nồng độ 1 và 3 cao hơn so với nồng độ 2 và 4 . Tuy nhiên, sau 60 ngày khi bắt đầu từ cây giống $0,2 \mathrm{~cm}$ cho thấy: Ở nồng độ 4 , không có sự tăng trưởng về chiều dài và rộng của lá, trong thời gian từ 2 tháng đến 6,5 tháng tuổi (hình 1 ) và ở nồng độ 3 cây rong Mơ con cũng phát triển chậm dần sau 90 ngày. Điều này cho thấy, nguồn dinh dưỡng ở nồng độ 4 đã hạn chế sự phát triển của cây con từ giai đoạn hợp tử khi so sánh với các nồng độ khác (kiểm chứng bằng t-test cũng cho thấy sự khác nhau rõ ràng, $\mathrm{p}<0,01)$. Trong khi, nồng độ 3 phù hợp cho cây con ở giai đoạn non 
đến 90 ngày tuổi, nhưng sau đó lại cản trở sự phát triển. Nồng độ 1 và 2 đều có ảnh hưởng tốt đến sự phát triển cây con từ giai đoạn hợp tử cho đến cây con cao $1,28 \pm 0,14 \mathrm{~cm}$. Sau 6,5 tháng tuổi, chiều dài cây giống cao nhất vẫn ở nồng độ $1(1,48 \pm 0,30 \mathrm{~cm})$ và chúng có khuynh hướng giảm dần lần lượt là $0,78 \pm$ $0,17 \mathrm{~cm} ; 0,48 \pm 0,07 \mathrm{~cm}$ và $0,38 \pm 0,05 \mathrm{~cm}$ khi nồng độ dinh dưỡng tăng dần từ nồng độ 1 lến nồng độ 4 . Sự khác nhau về chiều dài và chiều rộng lá là có ý nghĩa thống kê (ANOVA: $\mathrm{f}=10,23>\mathrm{f}_{\text {crist }}=3,23 ; \mathrm{p}<0,01$ ) (hình 1,2 ).

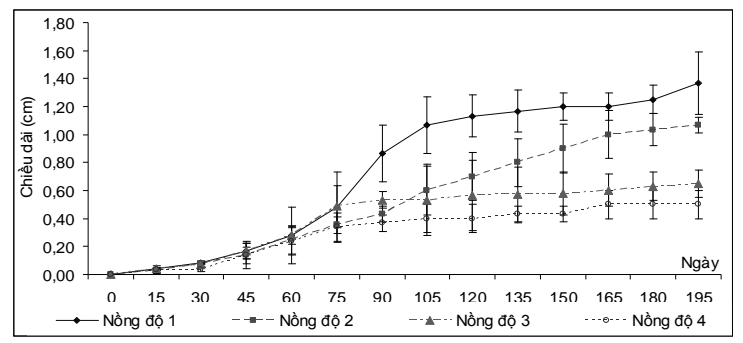

Hình 1. Sự phát triển của cây con rong Mơ ở nồng độ dinh dưỡng khác nhau theo thời gian

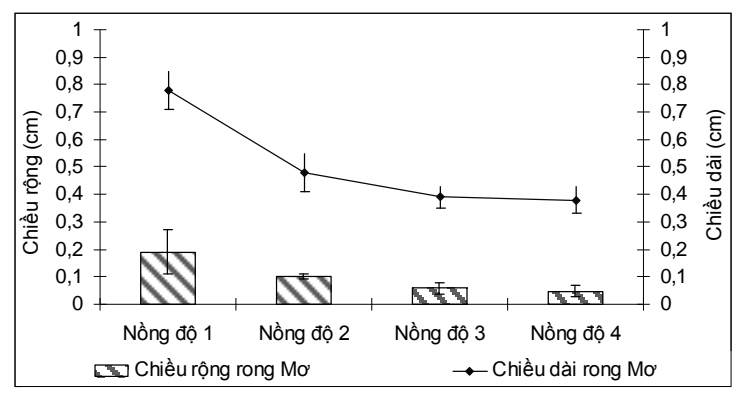

Hình 2. Sự phát triển của rong Mơ theo nồng độ dinh dưỡng (tăng dần từ nồng độ 1 đến nồng độ 4)

Kết quả này cũng phù hợp với nghiên cứu của Hsiao [3]. Theo ông, khi nghiên cứu ảnh hưởng của dinh dưỡng lên sự phát triển của Laminaria saccharina cho thấy từ nồng độ $5 \mu \mathrm{gN}-\mathrm{NO}_{3} / \mathrm{L}$ và $5 \mu \mathrm{gP}-\mathrm{PO}_{4} / \mathrm{L}$ đã bắt đầu ảnh hưởng đến sinh trưởng và gia tăng tốc độ $\sinh$ trưởng theo nồng độ nhưng khi nồng độ trên $588 \mu \mathrm{gN}-\mathrm{NO}_{3} / \mathrm{L}$ và $15 \mu \mathrm{gP}-\mathrm{PO}_{4} / \mathrm{L}$ đã hạn chế sự phát triển của cây con. Theo Schaffelke \& Klumpp [8], rong Mơ S. baccularia có tốc độ sinh trưởng cao nhất ở $\left(208 \mu \mathrm{gN}-\mathrm{NH}_{4} / \mathrm{L}\right)$ $4,8 \mu \mathrm{M}$ amoni và $\left(29,4 \mu \mathrm{gP}-\mathrm{PO}_{4} / \mathrm{L}\right) 0,3 \mu \mathrm{M}$ phốt phát và sau đó giảm dần khi nồng độ $\mathrm{N}$ và $\mathrm{P}$ tăng. Điều này cũng cho thấy, hàm lượng $\mathrm{N}$ và $\mathrm{P}$ trong mô có tăng lên khi nồng độ dinh dưỡng tăng, nhưng hàm lượng $\mathrm{N}$ và $\mathrm{P}$ tích lũy trong mô cũng chỉ đến mức bão hòa là $2,5 \% /$ trọng lượng khô cho $\mathrm{N}$ và $0,22 \% /$ trọng lượng khô cho $\mathrm{P}[8]$. Tuy nhiên, nồng độ này là thấp hơn so với kết quả nghiên cứu của Shao et al. [9], khi nghiên cứu về dinh dưỡng trong nuôi trồng cây con loài Sagarssum horneri, nhưng do thí nghiệm của tác giả thay nước có thời gian ngắn hơn, từng 2 ngày một lần và bón

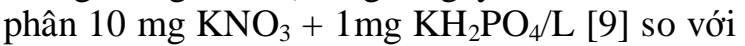
thời gian thay nước của nghiên cứu này, cũng như của Hsiao và Schaffelke \& Klumpp [3, 8] là 1 tuần đến 2 tuần.

\section{Ảnh hưởng ánh sáng đến phát triển của cây giống rong Mo}

Ảnh hưởng của các ánh sáng lên sự phát triển của cây con rong Mơ theo thời gian từ khi bắt đầu từ hợp tử đển 60 ngày, cho thấy cây giống phát triển ở hai mức ánh sáng 1.1 và 1.2 cao hơn so với 1.3 và 1.4 . Tuy nhiên sau 60 ngày khi bắt đầu từ cây giống $0,2 \mathrm{~cm}$ cho thấy có sự suy giảm về chiều dài và rộng của lá ở ánh sáng 1.1 và đến 90 ngày có sự suy giảm về chiều dài và rộng của lá ở ánh sáng 1.2. Trái lại, có sự gia tăng cao về phát triển chiều dài ở các mức ánh sáng 1.3 và 1.4 trong thời gian từ 2 tháng đến 6,5 tháng tuổi (hình 3 ). Điều này cho thây, nguồn ánh sáng 1.3 và 1.4 đã hạn chế sự phát triển của cây con từ giai đoạn hợp tử đến giai đoạn cây giống cao $0,2 \mathrm{~cm}$ khi so sánh với 2 cường độ ánh sáng 1.1 và 1.2 (kiểm chứng bằng $\mathrm{t}$-test cũng cho thấy sự khác nhau rõ ràng, $\mathrm{p}<0,01)$. Ngược lại, sau thời gian 60 75 ngày tuổi, nguồn ánh sáng 1.1 và 1.2 đã hạn chế sự phát triển của cây con từ giai đoạn cây con cao $0,2 \mathrm{~cm}$ đến giai đoạn cây giống cao $1,5 \mathrm{~cm}$ khi so sánh với 2 cường độ ánh sáng 1.3 và 1.4 (kiểm chứng bằng $\mathrm{t}$-test cũng cho thấy sự khác nhau rõ ràng, $p<0,01)$. Ánh sáng 1.3 và 1.4 có ảnh hưởng tôt đến sự phát triển cây con từ giai đoạn cây con cao $0,2 \mathrm{~cm}$ cho đến $1,5 \mathrm{~cm}$. Sau 6,5 tháng tuổi, chiều dài cây giống cao nhất ở mức ánh sáng $1.4(1,48 \pm 0,30 \mathrm{~cm})$ và chúng có khuynh hướng giảm dần lần lượt là $1,38 \pm 0,70 \mathrm{~cm} ; 1,27 \pm 0,40 \mathrm{~cm} ; 0,90 \pm 0,40 \mathrm{~cm}$ khi ánh sáng giảm dần dần từ ánh sáng 1.4 xuống 1.1. 
Kết quả này cũng phù hợp với nghiên cứu của Choi và cộng sự khi nghiên cứu ảnh hưởng ngưỡng ánh sáng $20-80 \mu \mathrm{mol}$ photon $/ \mathrm{m}^{2} / \mathrm{s}$ đối với của rong $S$. horneri, cho thấy chúng phát triển tốt nhất ở ánh sáng thấp $25 \mu \mathrm{mol}$ photon $/ \mathrm{m}^{2} / \mathrm{s}$ trong giai đoạn cây con dưới $0,2 \mathrm{~cm}$ [2]. Tương tự, Zhao et al. [10], khi nghiên cứu ngưỡng ánh sáng $9-88 \mu \mathrm{mol}$ photon $/ \mathrm{m}^{2} / \mathrm{s}$ ảnh hưởng lên sự phát triển của cây rong Mơ con $S$. thunbergii cho thấy giai đoạn cây con dưới $0,2 \mathrm{~cm}$ tăng trưởng tốt nhất ở điều kiện ánh sáng thấp $44 \mu \mathrm{mol}$ photon $/ \mathrm{m}^{2} / \mathrm{s}$. Tuy nhiên, Hwang và cộng sự thấy rằng ở giai đoạn ươm giống từ $0,2 \mathrm{~cm}$ đến $2,5 \mathrm{~cm}$, cây rong Mơ con có yêu cầu ánh sáng cao hơn so với giai đoạn $0-0,2 \mathrm{~cm}$, trung bình $488 \pm$ $58 \mu \mathrm{mol}$ photon $/ \mathrm{m}^{2} / \mathrm{s}$ là tốt nhất [4].

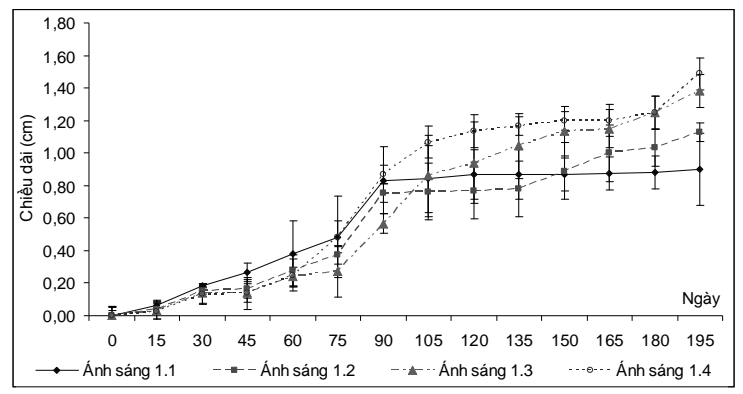

Hình 3. Sự phát triển của cây con rong Mơ ở mức ánh sáng khác nhau theo thời gian

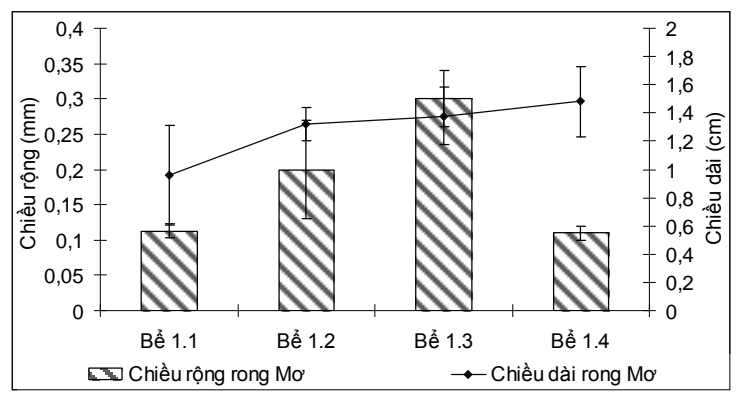

Hình 4. Sự phát triển của rong Mơ theo ánh sáng (tăng dần từ bể 1.1 đến bể 1.4)

Theo dõi ảnh hưởng của ánh sáng đến phát triển của rong Mơ cho thấy, khi ánh sáng tăng thì chiều rộng phiến lá tăng, nhưng chiều dài ngắn lại. Nhưng ở lô 1.4 với ánh sáng cao nhất, thì rong Lục phát triển mạnh đã cạnh tranh ánh sáng của rong Mơ, làm lá rong Mơ phát triển ngược với $\mathrm{xu}$ hướng trên, tăng chiếu dài và giảm chiều rộng, điều này có thể là một cơ chế giúp lá rong Mơ có điều kiện nhận được ánh sáng (khi bị rong Lục che bóng) (hình 5). Tuy nhiên, ở mức ánh sáng lô 1.3 , rong Mơ phát triển tốt với diện tích lá lớn nhất trong các mức ánh sáng nghiền cứu $(\mathrm{p}<0,05)$ (hình 4,6$)$. Kết quả này là phù hợp với Hwang et al., [4], cho rằng cây rong $M o ̛$ con ở giai đoạn $\mathrm{I}$ từ 0,2 $0,5 \mathrm{~cm}$ phát triển tốt ở mức nước sâu $1,5 \mathrm{~m}$ tương ứng với ánh sáng có cường độ trung bình $488 \pm 58 \mu \mathrm{mol}$ photon $/ \mathrm{m}^{2} / \mathrm{s}$.

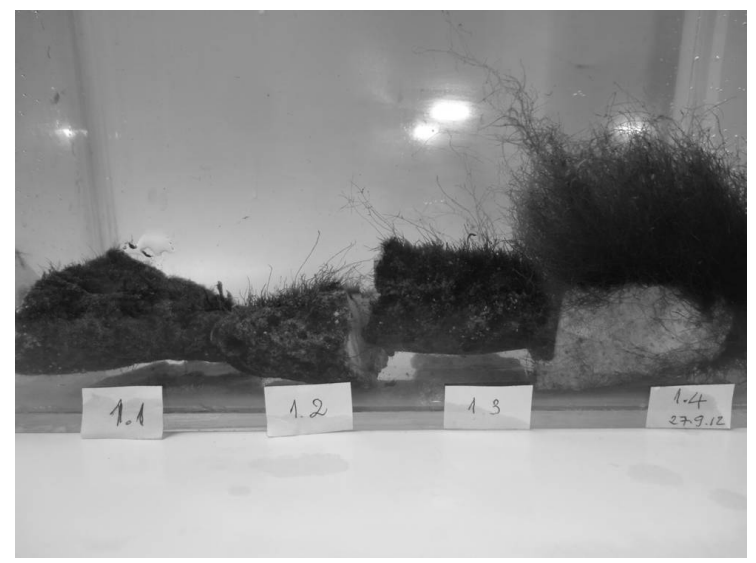

Hình 5. Sự phát triển của rong Lục theo cường độ ánh sáng (tăng dần từ 1.1 đến 1.4 )

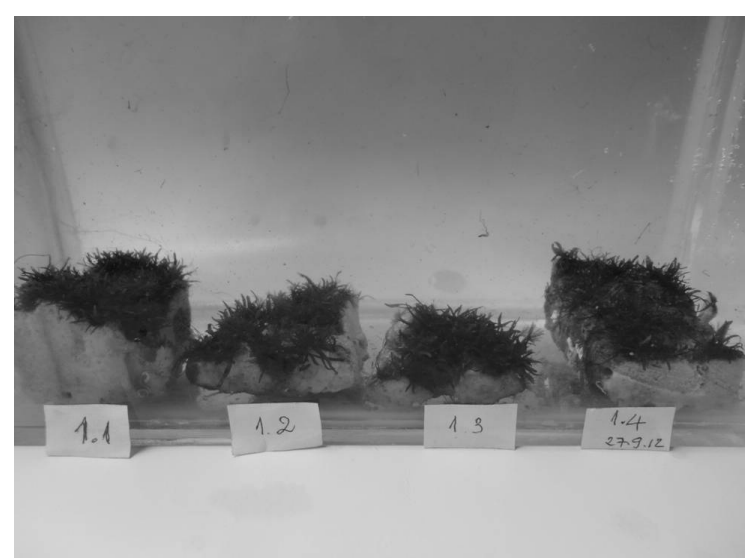

Hình 6. Sự phát triển của rong Mơ theo cường độ ánh sáng (tăng dần từ 1.1 đến 1.4)

\section{Sự phát triển của rong Mơ theo ánh sáng và dinh dưỡng}

Như vậy, kết hợp hai yếu tố vừa ánh sáng và dinh dưỡng cho thấy rằng, chiều dài có sự khác nhau rõ rệt giữa các lô có nồng độ khác 
nhau ( $\mathrm{p}=0,003)$, trong đó chiều dài lớn nhất ở nồng độ 1 và ở mức ánh sáng $4(1,48 \pm$ $0,30 \mathrm{~cm}$ ) và chiều rộng thì không có sự khác nhau có ý nghĩa thồng kê $(\mathrm{p}>0,05)$. Tuy nhiên chiều rộng lớn nhất ở nồng độ 1 và ở mức ánh sáng $3(0,36 \pm 0,11 \mathrm{~cm})$. Xét về diện tích lá, cho thấy diện tích lá lớn nhất ở nồng độ 1 và ở mức ánh sáng 3 (hay lô 1.3), tương ứng với hàm lượng dinh dưỡng là $4 \mathrm{mg} \mathrm{NaNO}_{3}+0,4 \mathrm{mg}$ $\mathrm{KH}_{2} \mathrm{PO}_{4} / \mathrm{L}$ và mức ánh sáng là $510 \mu \mathrm{mol}$ photon $/ \mathrm{m}^{2} / \mathrm{s}$. Kết quả thể hiện ảnh hưởng kết hợp hai yếu tố ánh sáng và dinh dưỡng lên kích thước cá thể rong Mơ sau 6,5 tháng nuôi trồng trong bể thí nghiệm ở bảng 1 và hình 7 .

Bảng 1. Hình thái cây rong Mơ theo ánh sáng (4 mức ánh sáng tăng từ trái sang phải và 4 mức dinh dưỡng tăng từ trên xuống dưới)

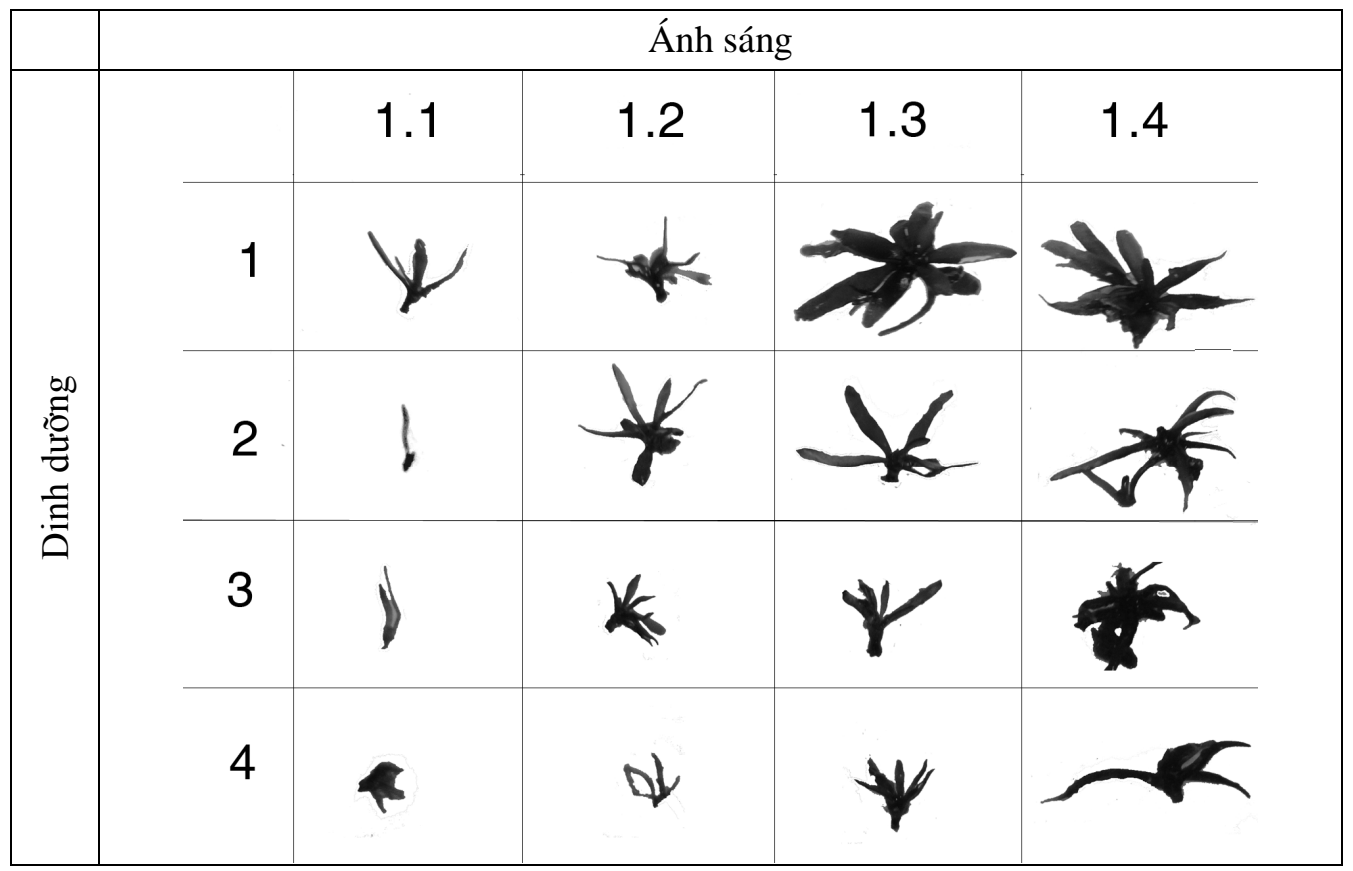
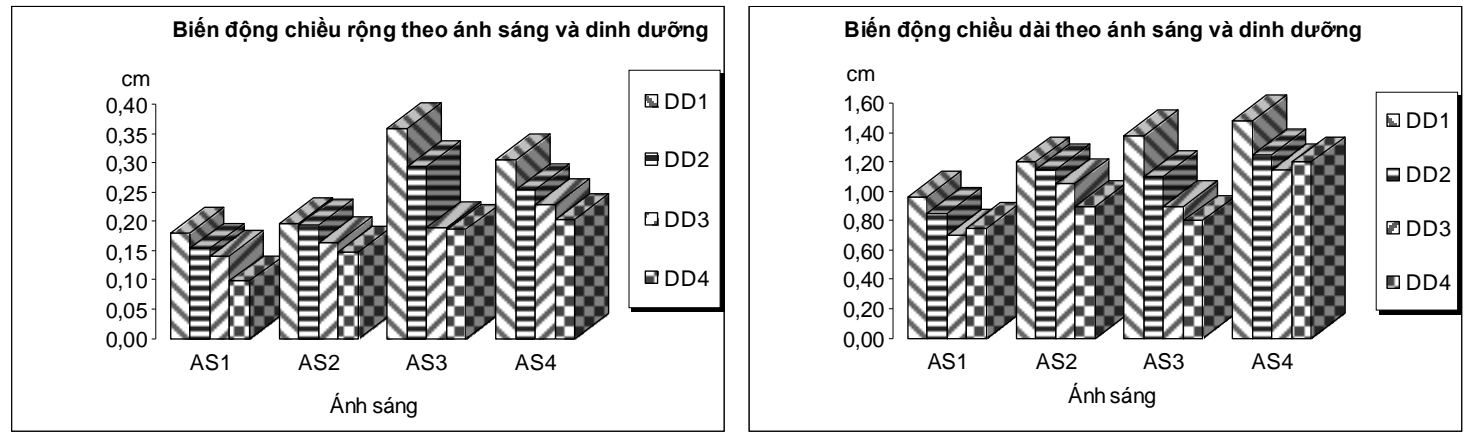

Hình 7. Biến động chiều dài và rộng cây rong Mơ theo ánh sáng (AS) và dinh dưỡng (DD) tăng dần từ mức 1 đến mức 4

So sánh sự phát triển của cây rong Mơ trồng trong phòng thí nghiệm và tự nhiên

Sau 4 tháng nuôi trồng từ cây con cao $0,2 \mathrm{~cm}$ vừa ở trong bể kính vừa ở ngoài tự nhiên cho thấy: cây rong Mơ ươm giống ngoài tự nhiên (Đầm Báy, Nha Trang: $\left.12^{\circ} 11^{\prime} 48,57^{\prime \prime N}, 109^{\circ} 17^{\prime} 31,63^{\prime \prime} \mathrm{E}\right)$ phát triển tồt sau 4 tháng rong dài trung bình $2,4 \pm 0,3 \mathrm{~cm}$ đạt được chiều dài của cây giống để nuôi trồng 
theo mô hình thương phẩm là $2,5 \mathrm{~cm}[11,12]$. Trong khi đó, cây con nuôi trồng trong bể kính ở điều kiện thí nghiệm thì rong phát triển rất chậm, chiều dài trung bình cho các lô thí nghiệm chỉ đạt $0,78 \pm 0,30 \mathrm{~cm}$ (hình 8,9 ). Điều này có thể do nhu cầu về ánh sáng, dinh dưỡng, khoáng vi lượng cao ở giai đoạn ươm giống tù̀ $0,2 \mathrm{~cm}$ đến $2,5 \mathrm{~cm}$.

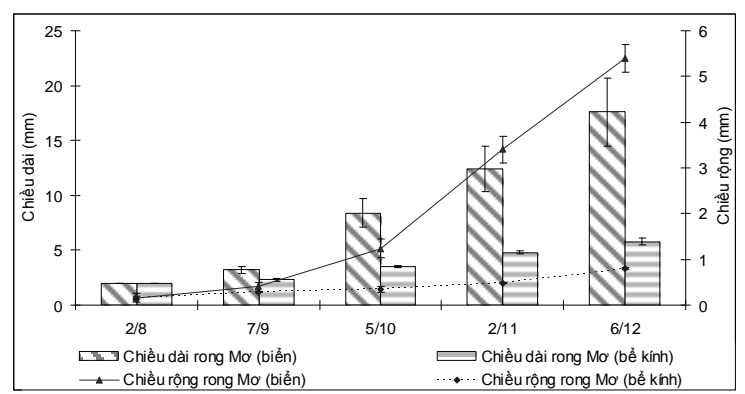

Hình 8. Sự phát triển của cây rong Mơ con trong bể kính và ngoài tự nhiên sau 4 tháng nuôi trồng

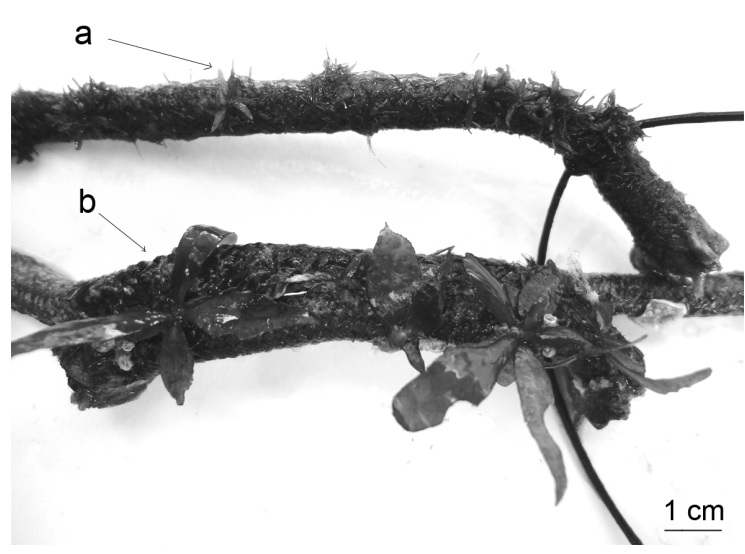

Hình 9. So sánh hình thái cây rong Mơ con trồng trong phòng thí nghiệm (a) và tự nhiên sau 4 tháng nuôi (b)

\section{KẾT LUẬN}

Cây con cao $0,2 \mathrm{~cm}$ và đạt mật độ 2 - 3 cây $/ \mathrm{cm}$ sau 60 ngày nuôi cây con từ hợp tử, đáp ứng yêu cầu tiêu chuẩn cây giống cho giai đoạn ươm.

Hàm lượng dinh dưỡng $\mathrm{NaNO}_{3}: \mathrm{KH}_{2} \mathrm{PO}_{4}=$ 4:0,4 $\mathrm{mg} / \mathrm{L}$ và mức ánh sáng $510 \mu \mathrm{mol}$ photon $/ \mathrm{m}^{2} / \mathrm{s}$ tốt cho sự phát triển của cây rong Mơ con và hạn chế sự phát triển của rong tạp.
Sự phát triển của cây con trong bể kính ở điều kiện phòng thí nghiệm trong giai đoạn ươm giống từ $0,2 \mathrm{~cm}$ đến $2 \mathrm{~cm}$ là rất chậm, không thể đáp ứng được tiêu chuẩn cây giổng sau thời gian ươm.

Lò̀i cảm ơn: Công trình này được thực hiện bởi kinh phí của Viện Hàn lâm Khoa học và Công nghệ Việt Nam cho hướng nghiên cứu Khoa học và Công nghệ biển.

\section{TÀI LIỆU THAM KHẢO}

1. Bùi Minh Lý, Trần Thị Thanh Vân, Đặng Xuân Cường, 2009. Sàng lọc hoạt tính kháng khuẩn của một số loài rong biển Khánh Hòa, Tuyển tập Hội nghị Khoa học Toàn quốc về Sinh học biển và phát triển bền vững, 671-677.

2. Choi H. G., Lee K. H., Yoo H. I., Kang P. J., Kim Y. S., Nam K. W., 2008. Physiological differences in the growth of Sargassum horneri between the germling and adult stages. J. Appl. Phycol., 20: 729735 .

3. Hsiao S. I. C., 1972. Nutritional requirements for gametogenesis in Laminaria saccharina (L.) Lamouroux. Thesis (Ph.D.) - Simon Fraser University, 1972, 131pp.

4. Hwang E. K., Baek J. M., Park C. S., 2007. Assessment of optimal depth and photon irradiance for cultivation of the brown alga, Sargassum fulvellum (Turner) C. Agardh J Appl Phycol 19: 787-793.

5. Lê Nhu Hậu, Bùi Minh Lý, 2011. Tiềm năng và giải pháp phát triển nguồn lợi rong Mơ tại các tỉnh miền Trung. Hội thảo quốc tế trong Điều tra, Nghiên cứu Tài nguyên và môi trường biển. Tr. 305-312.

6. Nguyến Hũu Đại, 1997. Rong Mơ (Sargassaceae) Việt Nam. Nguồn lợi và sử dụng. NXB Nông nghiệp TP Hồ Chí Minh, 198 tr.

7. Pang S. J., Gao S. Q., Sun J. Z., 2006. Cultivation of the brown alga Hizikia fusiformis (Harvey) Okamura: Controlled fertilization and early development of seedlings in raceway tanks in ambient light and temperature. J Appl Phycol 18: 723-731. 
8. Schaffelke B. and Klumpp D. W., 1998. Nutrient-limited growth of the coral reef macroalga Sargassum baccularia and experimental growth enhancement by nutrient addition in continuous flow culture. Mar. Ecol. Prog. Ser.,19: 199-211.

9. Shao J. P., Feng L., Ti F. S., 2009. Cultivation of the brown alga Sagarssum horneri: Sexual reproduction and seeding production in tank culture under reduced solar irradiance in ambient temperature. J Appl Phycol, 21: 413-422.

10. Zhao, Z., Zhao, F., Yao, J., Lu J., Ang, P. O. J., Duan D., 2008. Early development of germling of $S$. thunbergii (Fucales,
Phaeophyta) under laboratory conditions. J. Appl. Phycol., DOI 10.1007/s10811-0889311-y.

11. Xie E. Y., Liu D. C., Jia C., Chen X. L. and Yang B., 2012. Artificial seed production and cultivation of the edible brown alga Sargassum naozouense Tseng et Lu. J Appl Phycol DOI 10.1007/s10811-012-9885-2.

12. Zhang Q. S., Tang Y. Z., Liu S. K., Zhang S. B., Lu Z. C., Cu S. H. and Yu Y. Q., 2012. Zygote-derived seedling production of Sargassum thunbergii: Focus on two frequently experienced constraints in tank culture of seaweed. J. Appl. Phycol., DOI 10.1007/s10811-011-99689-9. 
Lê Như Hậu, Vũ Thị Mơ, Võ Thành Trung, ...

\title{
AFFECTS OF LIGHT AND NUTRIENT IN ARTIFICAL SEEDLING PRODUCTION FROM ZYGOTES OF SARGASSUM POLYCYSTUM C. AGARDH
}

\section{Le Nhu Hau, Vu Thi Mo, Vo Thanh Trung, Tran Van Huynh, Tran Nguyen Ha Vy}

Nha Trang Institute of Technology Research and Application, VAST

\begin{abstract}
Increasing the growth of germlings and decreasing fouling algae are two main constraints for the seedling production of Sargassum in laboratory condition. These results indicate that the growth of germlings was best in nutrient concentration of $\mathrm{NaNO}_{3}: \mathrm{KH}_{2} \mathrm{PO}_{4}=4: 0,4 \mathrm{mg} / \mathrm{L}$ and photon irradiance of $510 \mu \mathrm{mol}$ photon $/ \mathrm{m}^{2} / \mathrm{s}$. During the experiment, fouling was controlled by degration of photon irradiance. Seedlings of $>0.2 \mathrm{~cm}$ length could be achieved after 2 month of tank culture. However, seedlings of $2 \mathrm{~cm}$ length could be achieved after 4,5 month of tank culture from seedlings of $0.2 \mathrm{~cm}$ length. These results indicate that the growth of seedling was low during their nursery cultivation stage at laboratory. Therefore, successful cultivation in nursery stage is essential for field conduction.
\end{abstract}

Key words: Artificial seedling production, growth and development, Sargassum polycystum, photon irradiance and nutrient. 